\title{
Objectivity and quantification in lung disease
}

\author{
LYNNE REID \\ M.D., F.R.C.P., F.R.A.C.P., F.R.C.Path. \\ Department of Experimental Pathology, Cardiothoracic Institute, \\ Brompton Hospital, London SW3 6HP
}

\begin{abstract}
Summary
Methods of counting and measurement are described which have added much to the understanding of normal lung structure and hence function; these have identified important features of disease previously unsuspected and have permitted experimental analysis of these changes.
\end{abstract}

\section{Introduction}

Histopathologists have been slow to measure the tissue changes they have observed, slow even to count cell populations and thus they have failed to benefit as much as they might from what they have seen. In the last 20 years or so the application of quantitative methods of analysis has gained ground in research and, to a lesser extent, in diagnosis. This paper illustrates some of the methods that have been used in the study of lung disease, both human and experimental. The emphasis will be on measurement, numerate analysis and quantification as the way by which objectivity may be increased. Counting and measurement have contributed significantly to the determination of the pattern of lung growth and to our understanding of normal function and of the changes in disease. The following quotation from Kelvin (1968) may serve as a text: 'When you can measure what you are speaking about and express it in numbers, you know something about it. When you cannot express it in numbers, your knowledge is of a meagre and unsatisfactory kind: it may be the beginning of knowledge, but you scarcely in your thought advance to the stage of science'.

\section{Methods}

Airways, alveoli and blood vessels can be counted and their size measured in ways appropriate to the structure and to the problem being investigated. In the case of an airway, it may be important to know how many times it branches, how many orders or generations of divisions it shows. To count alveoli in their millions is more difficult.

In the last century, geologists developed techniques of sampling and quantitative analysis (see Chayes, 1954) which have been applied to tissue only this century (Chalkley, 1943). The principles are simple although rigorous proof of the methods' validity calls for advanced mathematics. Professor André Cournand stimulated the mathematician Gomez to apply these methods to study of the lung: Weibel and Dunnill worked with him (for details of the techniques see Dunnill, 1962a; Weibel and Gomez, 1962; Weibel, 1963).

If a block is made up of a core of material ' $A$ ' surrounded by material ' $B$ ', the areal distribution of ' $A$ ' and ' $B$ ' on any horizontal slice is the same as the volume distribution throughout the block (Fig. 1). Imagine a raisin cake with the raisins evenly distributed through the cake, the proportion of the area of one slice would be the same throughout and could be assessed by a method of point-counting. If the oven were not hot enough and the raisins had sunk to the bottom, point-counting of more than one slice would be necessary to give an adequate sample If the cake had been fixed in formalin before slicing the volume before and after fixing of the fresh cake would need to be known so that a shrinkage factor could be determined. If the cake contained cherries and walnuts, these could be included. Blocks of tissue are selected for microscopy by stratified random sampling. Point-counting of sections is carried out by a grid placed in the eyepiece.

For certain measurements the linear intercept method is useful (Dunnill, 1962a). If alveoli are

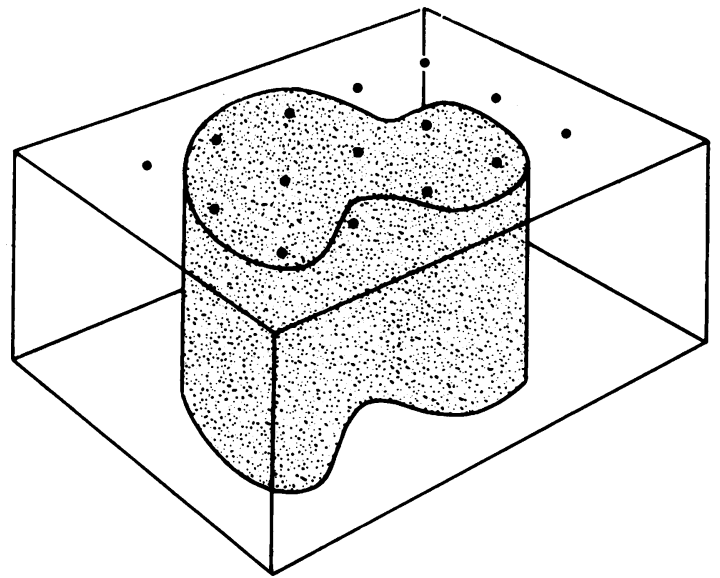

FIg. 1. Diagram of block with core of material A surrounded by material $B$. 

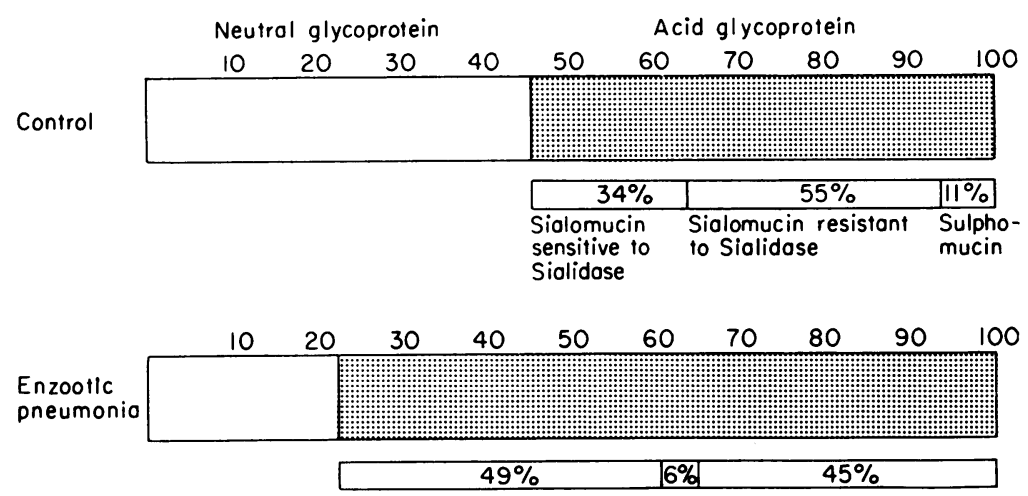

Fig. 2. Mean value: neutral and acid glycoprotein in pig bronchial submucosal gland mucous cells and each type of acid glycoprotein (as a percentage total gland area).

large. fewer alveolar walls will be transected by the line of a grid in the eyepiece. The number of alveolar walls intersected is a measure of alveolar size.

From the above it is apparent that methods have been developed for the analysis or 'quantitative morphometry of quite complex organs.

\section{Results}

\section{Glycoprotein in human submucosal gland}

The use of point-counting can be illustrated from histological studies of the human bronchial submucosal gland, both by light and electron microscopic examination.

The use of point-counting has helped in the analysis of the types of acid glycoprotein produced by the human bronchial submucosal gland. Alcian blue staining combined with the periodic-acid Schiff method stains acid glycoprotein blue, neutral glycoprotein red (Jones and Reid, 1972a, b). Refinements of the method can be made and used in serial sections so that the proportion of a range of acid glycoproteins can be estimated. In the human gland several types of sialomucin and of sulphomucin are present.

Sputum is such a mixture that histochemical analysis has made an important contribution to our understanding of the molecular types of glycoprotein. It has given us information that biochemical analysis could not.

In human disease, as in chronic bronchitis or cystic fibrosis, there is a shift in the proportion of the various types of acid glycoprotein, and a similar increase in acid glycoprotein, particularly sulphomucin, is seen also in bronchial irritation induced experimentally (Fig. 2) (Jones, Bolduc and Reid, 1972, 1973; Jones, Baskerville and Reid, 1975).

Point-counting methods have been adapted to ultrastructural analysis (Williams, 1969; Blackett and Parry, 1973). On the grid used in this application each point is placed within a circle. It is then possible? to estimate the size of the cell's organelles and theproportion of the cell constituted by the various organelles. Synthesis of glycoprotein in the humano bronchial submucosal gland can be traced in organo culture by the use of radioactive sugar and amigo acid precursors. The probable rate of a radioactive molecule responsible for the disintegration the reduces a halide nucleus and casts a shadow can determined by the use of the grid. The pattern of synthesis of acid glycoprotein by the serous and mucus cell of the human submucosal gland haso been analysed in this way (Meyrick and Reid, 1975) $\mathbb{Q}$ and the differences between the two cells determined. $\overrightarrow{\overrightarrow{0}}$

\section{Lung growth}

The newborn lung is not the adult in miniature Airways, alveoli and arteries each have a separate and distinctive pattern of growth. The pattern of growth can be summarized in the following three? Laws of Lung Development (Hislop and Reid,, 1974a).

(i) The bronchial tree is developed by the sixteentho week of intra-uterine life.

(ii) Alveoli develop after birth, increasing in number until the age of 8 years and in size until growth of the chest wall finishes with adulthood.

(iii) The pre-acinar vessels (arteries and veins) 0 follow the development of the airways, the intraacinar that of the alveoli. Muscularization of theo intra-acinar arteries does not keep pace with theo appearance of new arteries.

The full adult complement of airways-twenty $\stackrel{?}{+}$ five from the hilum to the diaphragm-is present when the lung is but a few centimetres in volume.

Alveoli, as we understand them in the adult, are 
not even present at birth, air spaces are but 'primitive saccules' as Boyden (1972) has called them. Of these, only 20 million are present and yet, by the age of 4 , five-sixths of the adult number of 300 million alveoli are present. The adult number is complete by the age of 8 (Dunnill, 1962b; Davies and Reid, 1970).

Blood vessels are to some extent covered by each of these Laws. The pre-acinar pulmonary arteries and veins follow the development of the airways, the intra-acinar that of the alveoli.

Childhood lobar emphysema. Lobar emphysema in the infant may present as an acute clinical emergency because of displacement and compression of intrathoracic structures by the enlarged lobe. Counting and measurement of airways, alveoli and blood vessels has identified several different pathological conditions that may cause it. Perhaps the most striking has been the condition of 'polyalveolar' lobe (Hislop and Reid, 1970) in which there is a 'giantism' of the lobe affecting only alveoli which may be five times as numerous as normal (Fig. 3). If airways are normal in number, as in these cases, it suggests that during the first half of intra-uterine life lung development was normal. If the airways are reduced in number and alveoli also, although the latter are abnormally large, then it seems that the lung can be regarded as congenitally hypoplastic (Henderson,

$\begin{array}{cc}\text { 'Polyalveolar } & \text { Normal } \\ \text { lobe } & 2 \text { days }\end{array}$

Left upper lobe
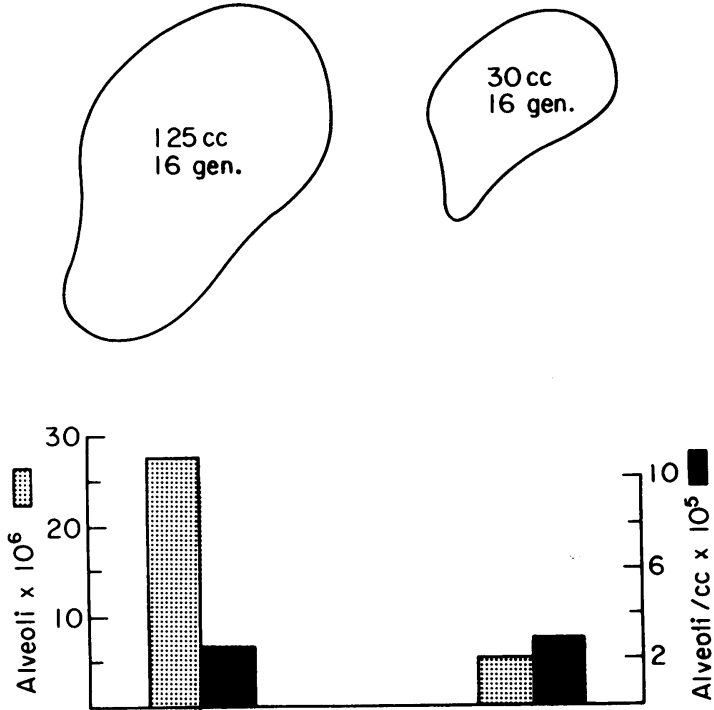

Fig. 3. Airway and alveoli findings in 'polyalveolar lobe' compared with those in a normal lung. Alveoli are increased in number but not in size.
Hislop and Reid, 1971). The number of airways and alveoli may be normal but the increase in alveolar size, i.e. emphysema can arise from overinflation due to twisting of the hilum (Hislop and Reid, 1971).

\section{Blood vessels}

The first requirement for precise measurement of vascular number and size is that the system be distended before fixation (Elliott and Reid, 1965). To identify artery or vein, at least one system must be injected. We use a suspension of barium (we use Micropaque) in gelatin, at a temperature of $60^{\circ} \mathrm{C}$ and a pressure of $100 \mathrm{cmH}_{2} \mathrm{O}$ maintained for 5-7 min. This technique allows section of tissue (Elliott and Reid, 1965). The pressure of $100 \mathrm{cmH}_{2} \mathrm{O}$ fills down to vessels of about $10 \mu \mathrm{m}$ in normal or diseased lung, fetal or adult, and does not pass through the capillary bed.

All arteries above $2000 \mu \mathrm{m}$ are elastic, between $2000 \mu \mathrm{m}$ and $150 \mu \mathrm{m}$ they are muscular. Below $150 \mu \mathrm{m}$ it is a little more complex. Along any arterial pathway the completely muscular wall gives way to a spiral of muscle before it disappears while still in vessels larger than capillaries (Fig. 4). The transition of muscular to partially-muscular and to non-muscular vessels does not always occur in arteries of the same size (n.b. 'artery' is applied to any vessel on the arterial size of the capillary bed larger than a capillary. This avoids using the term 'arteriole' which has a different significance for physiologist and anatomist). The structural characteristics of the peripheral arterial bed can be characterized by recording the size and structure of all small arteries in a given section of lung and analysing the total 'population' of arteries (Fig. 5). Wall thickness also can be predicted from external diameter (Reid, 1968 Appendix B)-the smallest arteries are relatively the most muscular.

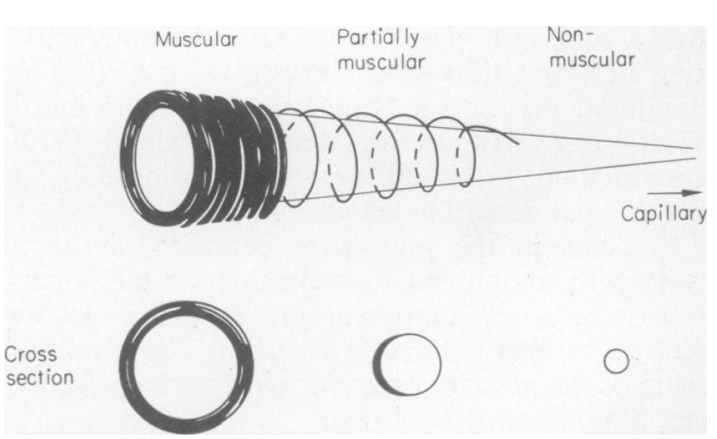

FIG. 4. Diagram representing the structure of a pulmonary artery at its distal end. In cross-section, vessels within the spiral region have a crescent of muscle and are termed 'partially muscular'. 


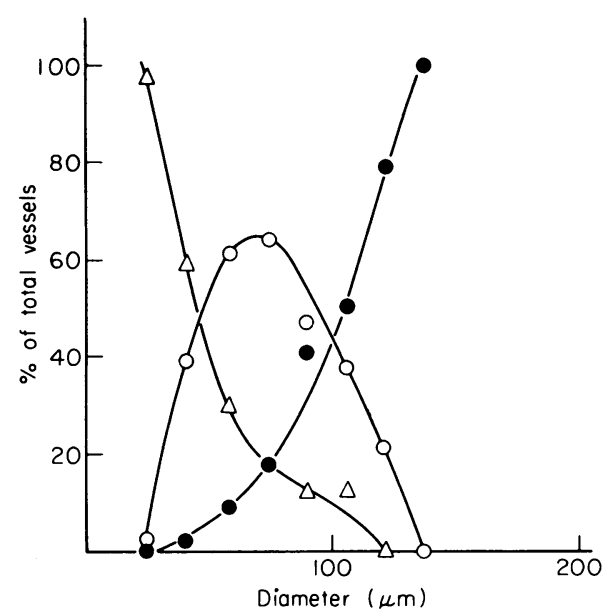

FIG. 5. Diagram illustrating 'population' distribution curves of arteries in the adult lung. In each size range the percentage of vessels with a given structure is shown; $\triangle$, muscular; $O$, partially muscular, $O$, non-muscular.

Law III of Lung Growth mentions that the partially muscular region and non-muscular structure are found in arteries of much larger size in the growing lung than in the adult (Hislop and Reid, 1973).

Muscularity of the arterial circulation (and a similar pattern has been found for the veins) can be assessed by wall thickness, relating muscle structure to arterial diameter. By 'landmarking' an artery according to its accompanying airway, the level within the lung to which muscle penetrates can be established. Artery number can also be related to alveolar number.

Primary pulmonary hypertension. Assessment of muscularity of the pulmonary circulation can be made from knowledge of wall thickness and of the degree of muscle extension to the periphery as judged either by arterial size or by position in the pattern of branching. Counting the number of arteries per unit area of lung section was first used in the study of the lung in cystic fibrosis to investigate the effect of childhood disease on lung growth, on the multiplication of small arteries (Reid and Ryland, 1973). The method produced new information also in primary pulmonary hypertension.

Findings in the lung were compared in three cases with undoubted thromboembolic pulmonary hypertension with a group of three cases in which the clinical features pointed as clearly to the condition being of the primary or cryptogenic variety (Anderson, Simon and Reid, 1973).

The arteriogram was a useful way to distinguish the two types. In primary pulmonary hypertension all axial arteries were patent, all tapered smoothly to the periphery but the background haze was diffusely and evenly reduced. In thromboembolic disease no@ filling occurred through large regions of lung with ${ }^{\complement}$ block apparent in large arteries.

In the cases of primary pulmonary hypertension measurement of wall thickness related to externa arterial diameter confirmed that there, in this sense, was increased muscularity of the pulmonary artery bed. But, unlike previous reports, no extension of muscle further to the periphery or into arteriesen smaller than is normal was found. Also, unexpect $\overrightarrow{0}$ edly, it was found that there was severe reductionin the number of small arteries less than $40 \mu \mathrm{m}$ inc diameter. In the cases with the longer clinicat history, dilatation lesions had developed. These were counted separately (Fig. 6). In the earliest case ant onion-skin lesion or ghost artery was seen through- out the lung, presumably representing a stage in thes disappearance of the arteries.

In a further case from whom biopsy material was examined, no such lesions were seen by light microo scopy but by electron microscopy it was possible to recognize similar changes within the arteries (Meyrick et al., 1974). It seemed then that the?

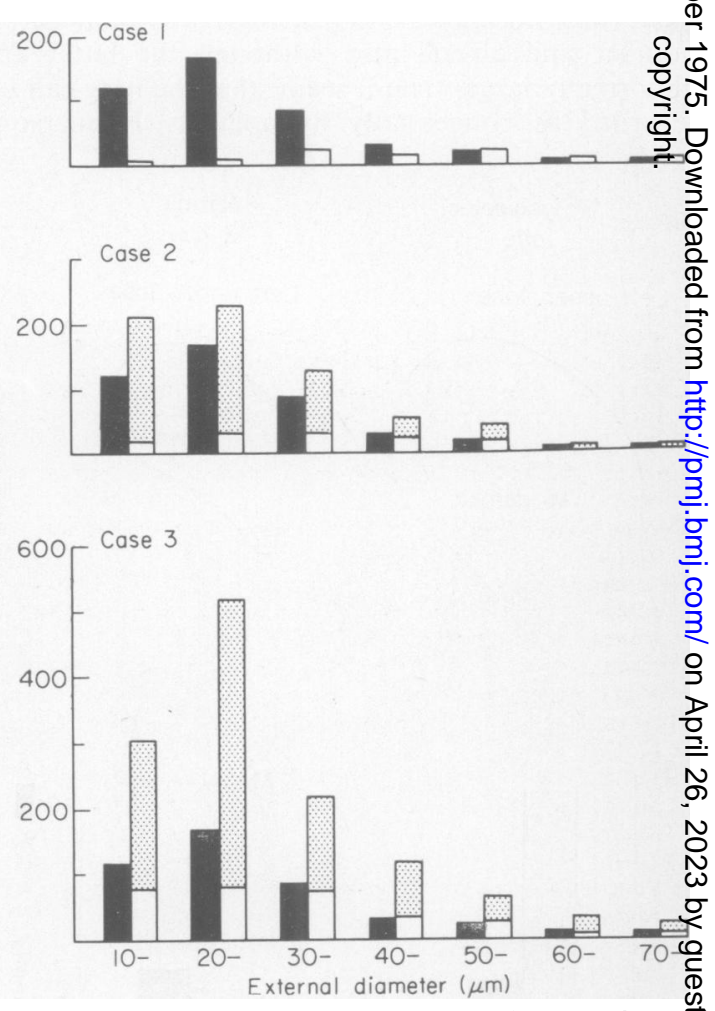

FIG. 6. Number of non-muscular arteries in $18 \mathrm{~mm}^{2}$ of lung tissue in three cases of primary pulmonary hypertension, compared with normal values. Normal; $\square$, primary pulmonary hypertension; : ":l:, arteries in dilatation lesions. 
reduction in the number of arteries in cystic fibrosis might, at least in part, represent changes associated with pulmonary hypertension rather than with hypoplasia.

Similar quantitative analysis has been made of the changes found in the lung of the rat in whom pulmonary hypertension has been produced by feeding with Crotalaria spectabilis (Hislop and Reid, 1974b). The ratio of left ventricle plus septum to right ventricle can be taken as the measure of right ventricular hypertrophy-Fulton's method has proved a considerable help to objectivity in assessing right ventricular hypertrophy (Fulton et al., 1952). Increase in wall thickness of the pulmonary arteries was found and also a reduction in the number of small arteries (Hislop and Reid, 1974b).

More recently, hypoxia has been shown to produce right ventricular hypertrophy with arterial muscle hypertrophy and reduction in the number of small arteries. Whereas onion-skin lesions have been identified with the light microscope after $C$. spectabilis feeding, they have not been seen after hypoxia (Hislop and Reid 1975). It is necessary now to refer this to the increased resolution offered by the electron microscope.

\section{References}

Anderson, G., Simon, G. \& ReID, L. (1973) Primary and thromboembolic pulmonary hypertension: a quantitative pathological study. Journal of Pathology, 110, 273.

BlacketT, N.M. \& PARRY, D.M. (1973) A new method for analysing electron microscope autoradiographs using hypothetical grain distributions. Journal of Cell Biology, 57, 9.

BOYDEN, A.E. (1972) Development of the human lung. In: Brennerman's Practice of Pediatrics, Vol. IV, Chap. 64. Harper and Rowe, Hagerstown.

Chalkley, H.W. (1943) Methods for quantitative morphologic analysis of tissue. Journal of the National Cancer Institute, 4, 47.

Chayes, F. (1956) Petrographic Modal Analysis. Wiley, New York.

DAviEs, G. \& ReID, L. (1970) Growth of the alveoli and pulmonary arteries in childhood. Thorax, 25, 669.

Delesse, M.A. (1847) Procédé mécanique pour déterminer la composition des roches. Compte rendu hebdomadaire des séances de l'Académie des sciences. Paris, 25, 544.

DunNILl, M.S. (1962a) Quantitative methods in the study of pulmonary pathology. Thorax, 17, 320 .

DunNiLl, M.S. (1962b) Postnatal growth of the lung. Thorax, $17,329$.

Elliott, F.M. \& Reid, L. (1965) Some new facts about the pulmonary artery and its branching pattern. Clinical Radiology, 16, 193.

Fulton, R.M., Hutchinson, E.C. \& Jones, A.M. (1952) Ventricular weight in cardiac hypertrophy. British Heart Journal, 14, 413.

Henderson, R., Hislop, A. \& Reid, L. (1971) New pathological findings in emphysema of childhood: 3 . Unilateral congenital emphysema with hypoplasia-and compensatory emphysema of contralateral lung. Thorax, 26, 195.

Hislop, A., Haworth, S.G., Shinebourne, E. \& Reid, L. (1975) Quantitative structural analysis of pulmonary vessels in isolated ventricular septal defect in infancy. British Heart Journal, (In press).
Hislop, A. \& ReID, L. (1970) New pathological findings in emphysema of childhood: 1. Polyalveolar lobe with emphysema. Thorax, 25, 682.

HisloP, A. \& REID, L. (1971) New pathological findings in emphysema of childhood: 2. Overinflation of a normal lobe. Thorax, 26, 190.

Hislop, A. \& ReID, L. (1973) Pulmonary arterial development during childhood: branching pattern and structure. Thorax, 28, 129.

Hislop, A. \& REID, L. (1974a) Growth and development of the respiratory system. In: Scientific Foundations of Paediatrics (Ed. by J. A. Davis and J. Dobbing), p. 214. Heinemann, London.

Hislop, A. \& Reid, L. (1974b) Arterial changes in Crotalaria spectabilis-induced pulmonary hypertension in rats. British Journal of Experimental Pathology, 55, 153.

Hislop, A. \& REID, L. (1975) Arterial changes in hypoxiainduced pulmonary hypertension in rats. (Submitted for publication.)

Jones, R., Baskerville, A. \& Reid, L. (1975) Histochemical identification of glycoproteins in pig bronchial epithelium (a) normal, and (b) hypertrophied from enzootic pneumonia. Journal of Pathology (in press).

Jones, R., Bolduc, P. \& ReID, L. (1972) Protection of rat bronchial epithelium against tobacco smoke. British Medical Journal, 2, 142.

Jones, R., Bolduc, P. \& ReID, L. (1973) Goblet cell glycoprotein and tracheal gland hypertrophy in rat airways: the effect of tobacco smoke with or without the antiinflammatory agent phenylmethyloxadiazole (PMO). British Journal of Experimental Pathology, 54, 229.

JONES, R. \& REID, L. (1973a) The effect of pH on Alcian Blue staining of epithelial acid glycoproteins. I. Sialomucins and sulphomucins (singly or in simple combinations). Histochemical Journal, 5, 9.

Jones, R. \& ReID, L. (1973b) The effect of pH on Alcian Blue staining of epithelial acid glycoproteins. II. Human bronchial submucosal gland. Histochemical Journal, 5, 19.

KeLvin, LoRD W.T. (1968) cited in Lancet, ii, 1381.

Meyrick, B., Clarke, S.W., Symons, C., Woodgate, D.J. \& ReID, L. (1974) Primary pulmonary hypertension. A case report including electronmicroscopic study. British Journal of Diseases of the Chest, 68, 11.

MEYRICK, B. \& REID, L. (1975a) In vitro incorporation of $\mathrm{H}^{3}$-threonine and $\mathrm{H}^{3}$-glucose by the serous and mucous cell of the human bronchial submucosal gland: a quantitative electron microscopic study. Journal of Cell Biology, (In press).

MEYRICK, B. \& ReID, L. (1975b) In vitro incorporation of $\mathbf{H}^{3}$-threonine and $\mathbf{H}^{3}$-glucose by the mucous cell of the human bronchial submucosal gland: a quantitative electron microscopic study. (Submitted for publication.)

ReID, L. (1968) The Pathology of Emphysema. Monograph. Lloyd-Luke (Medical Books), London.

REID, L. \& RYLAND, D. (1973) The pulmonary circulation in cystic fibrosis. In: Fundamental Problems of Cystic Fibrosis and Related Diseases (Ed. by John A. Mangos and Richard C. Talamo), p. 195. Symposia Specialists Medical Books, Miami, Florida.

WEIBEL, E.R. (1963) Morphometry of the Human Lung. Springer, Berlin.

WeIBEL, E.R. \& GoMEz, D.M. (1962) A principle for counting tissue structures on random sections. Journal of Applied Physiology, 17, 343.

Williams, M.A. (1969) The assessment of electron microscopic autoradiographs. In: Advances in Optical and Electron Microscopy (Ed. by R. Barer and V. E. Cosslett, Vol. 3, p. 219. Academic Press, New York and London. 